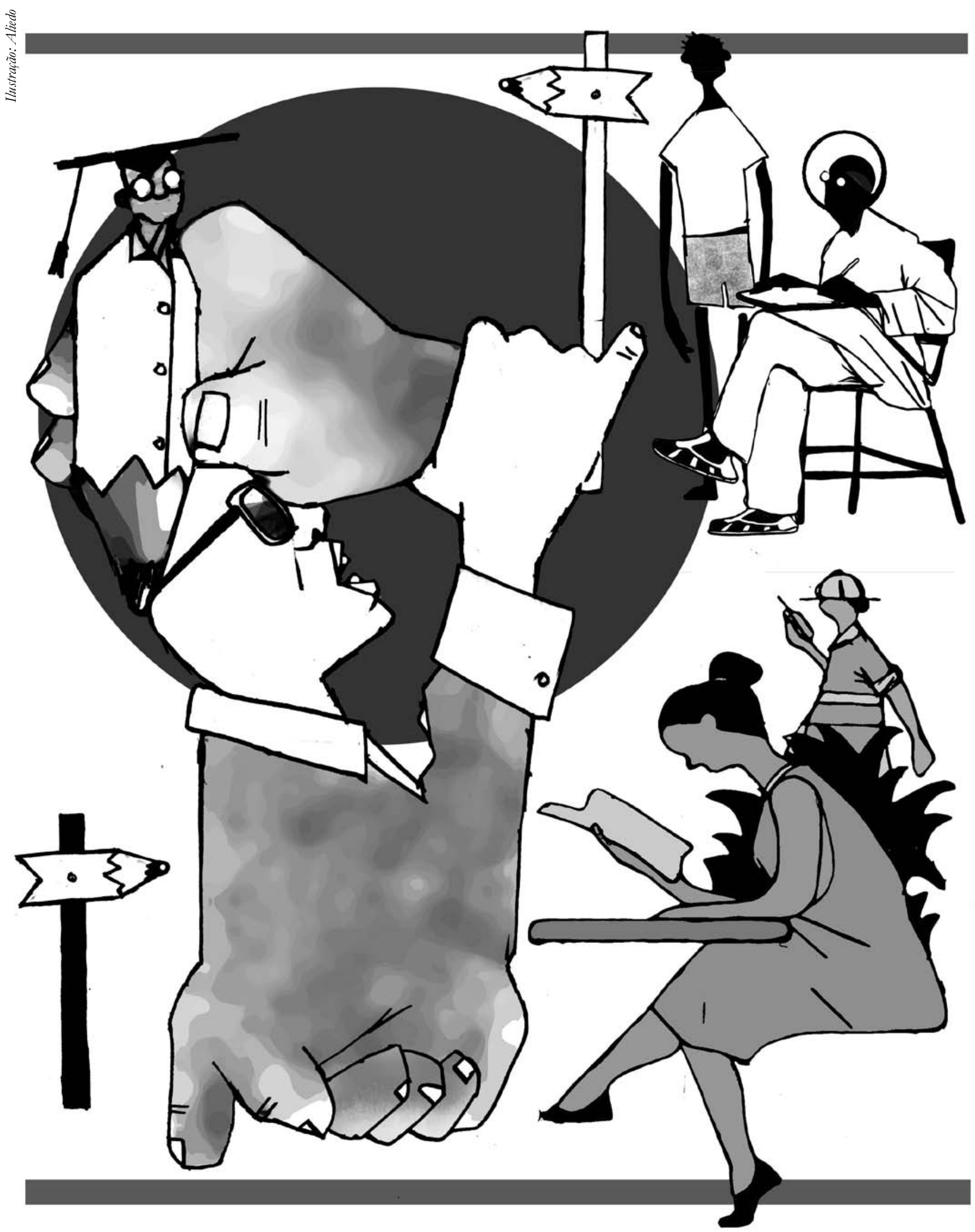




\title{
ForMACIÓN DE PROFESORES Y DIDÁCTICA: TENDIENDO PUENTES HACIA EL DESARROLLO PROFESIONAL Y DE LA ENSEÑANZA
}

\author{
Maria Cristina Davini*
}

\begin{abstract}
Resumo
Este artigo faz uma revisão crítica dos desencontros entre a formação de professores e a didática mantidos pelo discurso pedagógico das últimas décadas. Analisando os riscos dessa separação, afirma que o compromisso crítico, a reflexão e a autonomia profissional dos professores não são questões antagônicas à formação didática. Pelo contrário, o artigo destaca o valor dos critérios e regras básicas da ação didática, como base para decisões refletidas e contextualizadas por parte dos docentes.
\end{abstract}

Palavras-chave: Formação de Professores; Didática; Ensino; Profissão.

\section{INTRODUCCIÓN}

Desde hace ya varias décadas, venimos asistiendo a la crisis de confianza sobre el conocimiento didáctico y sobre su valor para la formación de los profesores. En ciertos casos, esta desconfianza se centró en la crítica al instrumentalismo tecnicista, dominante en décadas anteriores. En otros, se orientó hacia la búsqueda de reconfigurar el campo de estudios de la didáctica misma, relacionado con los problemas estructurales de la escolarización desde una perspectiva simultáneamente política y teórica ${ }^{1}$. Como denominador común, los debates y producciones se caracterizaron por la búsqueda de fortalecer el compromiso político con la justicia social y la inclusión de los sectores populares a las oportunidades de la educación.

A partir de entonces y acompañando ese proceso, la literatura especializada sobre la formación y la práctica docente crecieron notablemente tanto en volumen como en complejidad y profundidad analítica. Podría aún afirmarse que estas han constituído un insumo fundamental en el desarrollo de la teoría misma de la educación y la escolarización. Se profundizaron, así, los análisis sociológicos, políticos, simbólicos, etnográficos, los inter-subjetivos, entre muchas otras dimensiones y métodos de investigación.

En el plano didáctico, asistimos en estas décadas a la multiplicación de producciones para la enseñanza de distintos campos

\footnotetext{
Doctora en Educación por la PUC/RJ, Brasil, 1983-1989. Profesora Titular de Formación Docente, y en Maestría y Doctorado, Facultad de Filosofía y Letras de la Universidad de Buenos Aires (UBA), Argentina. Investigadora y Consultora en Organismos Nacionales e Internacionales.E-mail: cdavini@ciudad.com.ar
}

Recebido para publicação em: 28/02/08 de saber, de diversas disciplinas particulares, de distintos temas o problemas específicos. La multiplicidad de estudios adquirió una gran amplitud y fragmentación. Sin embargo, este movimiento no ha redundado en la construcción de certezas para la formación de los docentes que de respuestas claras para el desarrollo de la enseñanza. Como contrapartida, se ha ido abandonando la naturaleza propositiva de la intervención didáctica y su capacidad para formular criterios básicos y normas de acción, que ayuden a los profesores a tomar decisiones al enseñar en forma general y contextualizada ${ }^{2}$.

La formación de profesores se ha ido distanciando cada vez más (y por momentos de manera riesgosa) de la sistematización de algunas respuestas y criterios sistemáticos de acción para la enseñanza. Riesgosa, pues la enseñanza tiene una importancia y un efecto social sustantivo, dada su influencia ampliada y decisiva en la formación de niños, jóvenes y adultos. Ninguna empresa humana asumiría este desafío de proporciones a la espera de que la gente que la comanda o realiza cotidianamente pueda confiar exclusivamente en su intuición, inventiva o capacidad individual para la comprensión compleja.

Distantes de estos debates, existe hoy una importante producción en materia de diseño de la enseñanza y un acervo de metodologías que no alcanzan a difundirse entre los docentes ni son integradas a su formación. ¿Por qué no contar con orientaciones concretas?; ¿Qué factores o qué procesos han llevado a esta situación?. Analizarlos a todos ellos en profundidad y en sus múltiples interrelaciones constituye una empresa de largo alcance que excede el marco de esta reflexión. Sin embargo, algunas cuestiones pueden y merecen ser puntualizadas y, al menos, cuestionadas, para avanzar hacia su necesaria superación. 


\section{REVISITANDO EL PROBLEMA}

Siempre que existe una necesidad, se busca analizarla, conocerla y comprenderla a fin de construir alternativas de respuesta sistemática. La enseñanza no constituye una excepción, tal como lo muestra la historia. En el terreno de las prácticas, quienes enseñan y quienes se forman para enseñar necesitan contar con contribuciones didácticas y metodologías para operar en distintos contextos.

Sin embargo, estos puentes entre la formación de los docentes y la acción didáctica se han visto amenazados (cuando no obstruidos) desde ya hace un buen tiempo. Reconocer algunos hitos de este desencuentro puede arrojar alguna luz al problema.

En primer término, las producciones didácticas parecen no haberse recuperado aún del impacto del modelo tecnicista (notablemente de base conductista), diseminado en la década del 70 en la formación de profesores y en las bibliotecas docentes. Esta concepción reducía la enseñanza a una mera cuestión de aplicación neutral de procedimientos instrumentales, con nula consideración de las dimensiones contextuales, culturales e interpersonales. La crítica ha sido amplia, contundente y definitiva. Sin embargo, al cuestionar esta concepción, se arrojó al cesto de los materiales en desuso a cualquier intento de sistematización de métodos de enseñanza, visto como un resabio tecnocrático.

El proceso de crítica incluyó, también, el impacto de las teorías reproductivistas y de las investigaciones sociológicas. Ellas aportaron solidariamente a la comprensión de los mecanismos implícitos de segregación social de los sectores populares. El crecimiento notable de los estudios sociológicos críticos y de la ideología en las escuelas ha sido hegemónico, llevando a entender la violencia cultural y la dominación social en la escolarización y en la enseñanza. Más allá del aporte teórico y político de estas contribuciones, el desarrollo de propuestas de enseñanza quedó herido gravemente en el período.

No puede dejar de reconocerse, en esta visita al problema, el gran crecimiento de las teorías del currículo, que por su peso y volumen, dificultan notablemente la acción de los profesores a la hora de tener algunas certezas para enseñar. Schwab (1973) ${ }^{3}$ denominó críticamente a este fenómeno como "fugas teóricas", particularmente por la irrupción del discurso de los especialistas, y reclamó por la recuperación del lenguaje de las prácticas en las escuelas. A su vez, Kemmis (1988) ${ }^{4}$ destacó que uno de los grandes problemas de esta producción, se encuentra en la relación ente teorías y prácticas. La obra de Stenhouse $(1987)^{5}$ buscó acercar esta relación, ligando el currículo a la enseñanza de los profesores. Pero todas estas intenciones quedaron truncadas, dada la expansión de las reformas educativas recientes.

Esta nueva ola de reformas se centró en el currículo, a través de dos estrategias básicas: los cambios en los programas de estudios y la capacitación de los profesores para que los pongan en práctica. De esta forma, se ha ido generando un esquema burocrático para definir el currículo y una legión de funcionarios de distintos niveles: políticos del nivel central, profesionales técnicos y administradores centrales, políticos y administradores del nivel intermedio o local, supervisores etc. A su vez, pueden incluirse en esta gama, la influencia o participación de corporaciones y agencias sociales, económicas, culturales y gremiales.

Tanto las complejas construcciones teóricas especializadas como el creciente papel de las burocracias han producido un progresivo distanciamiento entre las propuestas curriculares y la realidad de las prácticas de la enseñanza en las escuelas.

A su vez, otros enfoques fenomenológicos han acentuado la interpretación de la enseñanza en el complejo espacio de la diversidad, de lo imprevisible, lo interpretativo o del mundo de la subjetividad. Pareciera ser difícil elaborar criterios generales de acción: si todo permanece en el mundo de lo particular, no existiría lugar para las regularidades.

Junto a la expansión de estas "megateorías" sociológicas y curriculares, los temas de la enseñanza se han ido diluyendo en "teorías diafragmáticas", ligadas a las didácticas específicas de contenidos particulares (DAVINI, 1996) ${ }^{6}$. Ante este todo disociado o de "convivencia forzada" se presenta un área vacante a la hora de orientar las prácticas docentes: una propuesta temática que trace puentes entre los aspectos más generales (pedagógicos, sociales, políticos y culturales) y los más específicos vinculados con la tarea de enseñar y de aprender.

Más allá de los aportes políticos o reflexivos, todos estos discursos constituyen un impacto del cual el pensamiento y la producción sobre y para la enseñanza parece no haberse recuperado suficientemente, al menos en algunos ámbitos.

Finalmente, este punteo del problema no puede dejar de lado el peso de las promesas sociales incumplidas de los sistemas educativos modernos y, particularmente, de las condiciones de organización del trabajo de enseñar y de aprender. Las formas de organización de las instituciones educativas y las condiciones reales de las prácticas no parecen ser objeto de cambios y mejoras, permaneciendo en general inalteradas. Desde el punto de vista didáctico, todo currículo adquiere su verdadero significado en las aulas y no puede ser comprendido por fuera de las condiciones 
sobre las que se desarrollan (FELDMAN, 1994) ${ }^{7}$.

Como balance, cabe reconocer que la didáctica ha recibido una carga de impactos muy sustantiva, lo que ha afectado a la formación y desarrollo docente en materia de criterios, normas y métodos generales para la mejora y eficacia de la enseñanza. Sin embargo, el problema estriba en definir si ello es suficiente argumento para la suspensión de estos puentes y aún para la negación del campo de conocimientos didácticos y de su naturaleza propositiva para orientar la enseñanza y la acción de los profesores.

Desde nuestro punto de vista, ello no sólo resulta improductivo y riesgoso, sino que en sí mismo nos encierra en un falso problema. En el contexto de lo social, son innumerables los ámbitos en que las prácticas se ven desviadas de sus mejores intenciones o sometidas a presiones de intereses, sin que por ello se eliminen los campos de producción de conocimientos y el desarrollo de alternativas de acción. Basta ver lo que ocurre con la cuestión del planeamiento urbano, de la contaminación del ambiente o de la salud pública (entre muchos otros), sin que por ello se deje de producir sistemáticamente para su cambio. Mientras tanto, desde la educación, las necesidades de la enseñanza y de los docentes permanecen, requiriendo establecer algunas certezas a la hora de enseñar, de criterios y reglas básicas de acción práctica ${ }^{8}$.

\section{LOS PROFESORES Y LA ENSEÑANZA: LA CONSTRUCCIÓN DE LA PROFESIÓN}

Si bien cualquier persona puede enseñar a otros, los docentes (maestros, profesores, tutores, capacitadores etc.) ejercen esta tarea como profesión, en ámbitos determinados de la enseñanza formal (escuelas, colegios, institutos, centros educativos, universidades) o en el mundo del trabajo. En esta profesión, la enseñanza deja de ser una tarea de amateurs, desplazando al enseñante empírico. Supone una racionalización y una especialización de un determinado saber y de sus prácticas.

La racionalidad de cualquier profesión consiste en "la consecución metódica de un fin determinado de manera concreta y de carácter práctico mediante el empleo de un cálculo cada vez más preciso de los medios adecuados"(GERTH, H.; WRIGHT, Mills, 1989) ${ }^{9}$. Desde esta perspectiva, la docencia se expresa en una práctica profesional específica que pone en funcionamiento los medios adecuados para la transmisión educativa conforme determinadas finalidades e intenciones.

Como en todo ejercicio de una profesión, una buena parte del "oficio" de enseñar se desarrolla en las experiencias prácticas: actuar en contextos concretos, atender a una diversidad de sujetos, trabajar sobre distintos contenidos, elaborar alternativas prácticas, aprender de la propia experiencia. No se trata de la simple suma de "años de oficio", sino de la capacidad de reflexionar y decantar la propia experiencia.

Pero como en toda profesión, su ejercicio no puede basarse sólo en el oficio práctico. Cualquier profesión (ingenieros, médicos, abogados, artistas) se apoya en un cuerpo de conocimiento y en criterios generales y reglas de acción práctica. En otros términos, se apoya en un espacio estructurado de conocimientos y en normas de acción, cuyo valor se puede analizar en sí mismas.

A su vez, estos conocimientos y criterios de acción serán reflexivamente analizados en función de casos, sujetos y ámbitos concretos y reelaborados, ajustándolos a las actuaciones particulares. Pero ello no elimina el valor de las normas y criterios generales. Por el contrario, en cualquier profesión, ellos son bases para las decisiones particulares. Los médicos atienden la salud de distintas personas y grupos sociales en contextos sociales diversos; un arquitecto desarrolla sus proyectos apropiados para el contexto sociocultural, urbano o de su cliente; un abogado interviene sobre casos concretos y particulares. Aunque cada caso constituye una situación y una experiencia particular, en todos los casos, los profesionales se basan en principios y reglas generales de intervención. Hasta un director de orquesta o un actor, por más creativa que sea su performance o por más inspiración que tengan, se basan en normas y criterios generales de actuación. Estas normas o criterios generales varían a lo largo del tiempo, enriquecidos por nuevos conocimientos y experiencias prácticas, pero en sí mismos, siempre existen.

La docencia no constituye una excepción. Requiere de principios y criterios básicos de intervención, es decir, aquellos que le posibiliten la consecución metódica de sus fines con los medios más adecuados. Además de conocer los contenidos que enseña, el docente necesita contar con normas básicas generales para la acción práctica de enseñar, a partir de las cuales pueda construir su propia experiencia.

$\mathrm{Y}$ esta es la contribución es la que debe brindar (y ha brindado históricamente) la didáctica, es decir, el campo de conocimientos que permite formular

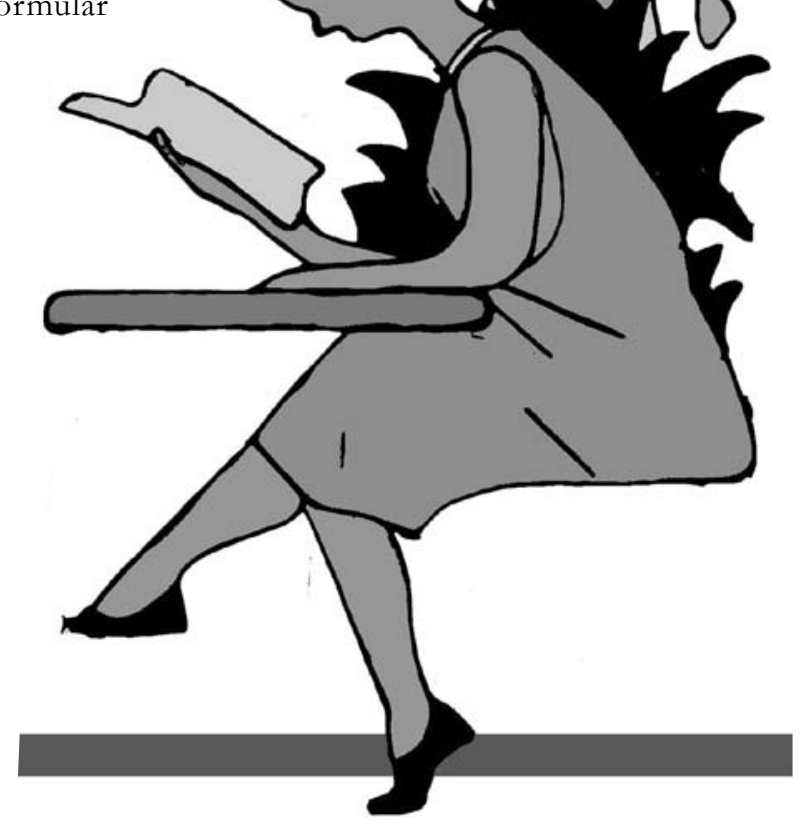




\section{los debates de los últimos}

\section{años sobre la profesión docente se han movido entre dos polos extremos: definir a la docencia como una semiprofesión, dados los marcos político-burocráticos de los sistemas escolares, o como actividad de intelectuales críticos.}

distintos criterios y desarrollos metodológicos en la enseñanza para alcanzar, en forma concreta y práctica, distintas intenciones educativas. En otros términos, ellos no constituyen criterios y métodos desvinculados de propósitos sociales, pedagógicos y humanos. Por el contrario, es (y con escasas excepciones siempre ha sido) el espacio de conocimientos que establece los nexos entre los fines educativos y el desarrollo de estructuras metodológicas apropiadas ${ }^{10}$.

Sin embargo, los debates de los últimos años sobre la profesión docente se han movido entre dos polos extremos: definir a la docencia como una semiprofesión, dados los marcos político-burocráticos de los sistemas escolares, o como actividad de intelectuales críticos.

El primero de los dos polos sostiene, fundamentalmente, el bajo desarrollo de la formación en conocimientos específicos consistentes y la organización del trabajo en las escuelas, como instituciones burocráticas. Ambos grupos problemas refieren claramente a razones extra- didácticas. En última instancia, ellas reflejan la distribución del poder y los principios de control social. De acuerdo con Bernstein (1980) ${ }^{11}$ habría que analizarlas en el marco de las formas a través de las cuales la sociedad selecciona, clasifica, distribuye y evalúa el conocimiento educativo considerado público y el papel que efectivamente se asigna a la docencia en estos marcos político-institucionales.

El segundo polo de argumentos, se basa en una saludable reacción tanto contra las lógicas político-burocráticas anteriormente citadas, como contra la hegemonía simplificadora del modelo tecnicista (APPLE, 1987; GIMENO SACRISTÁN, 1982; KEMMIS, 1988; DAVINI, 1991) ${ }^{12}$.
A partir de estas argumentaciones, la propuesta política y pedagógica consistiría fundamentalmente en destacar y sostener el papel de intelectuales críticos de los docentes (GIROUX, 1990) ${ }^{13}$, la comprensión de la complejidad de la enseñanza (GIMENO SACRISTÁN, J; PÉREZ GÓMEZ, A. 1996) ${ }^{14}$ y la autonomía profesional del profesor (CONTRERAS DOMINGO, 1996) ${ }^{15}$. Estos desarrollos han contribuido a recuperar la enseñanza en su potencial para la construcción de un proyecto educativo emancipador, crítico y participativo. En esta dirección, se también se ha destacado la necesaria autonomía reflexiva de los docentes para comprender y operar en situaciones complejas, irrepetibles y cambiantes.

Sin embargo, ambos polos del debate acaban teniendo un punto en común: declarar la ausencia de un cuerpo estructurado de conocimientos y de normas generales de acción y apelar solamente a la solución casi-artística, propia del mundo privado de un sujeto inspirado, comprometido y crítico, cuando se trata de enseñar. Junto con ello, se decretó (aunque sea en forma implícita) el fin de la didáctica, muchas veces considerada como representante del tecnicismo o por su incapacidad para abordar lo complejo.

Pero sostener estos enfoques a ultranza plantea nuevos y serios problemas. Implicaría confiar la enseñanza a una suerte de "providencialismo" en que algunos docentes más reflexivos, más formados y más críticos podrían hacer avanzar a la enseñanza, en desmedro de los otros. En el mejor de los casos, esto haría

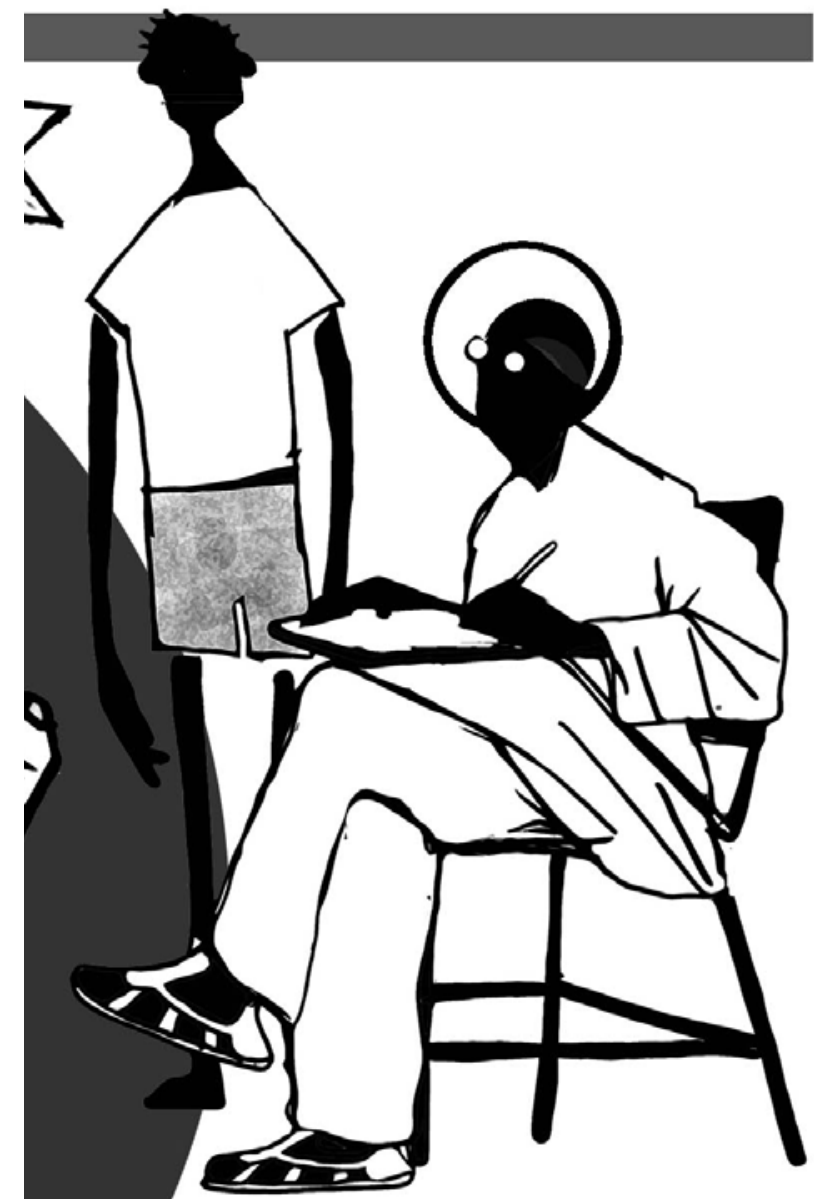


imposible distinguir la enseñanza (como práctica sistemática y social) de la producción artística individual. La cuestión puede acabar en límites políticamente riesgosos, si se consideran los efectos sociales y políticos de la enseñanza en las escuelas, afectando aún más a la educación de los sectores sociales populares. La enseñanza y la acción docente en las instituciones educativas no pertenece al mundo de las decisiones privadas sino una acción pública en la que hay que favorecer la mejor enseñanza para todos.

En este punto, es importante destacar, por fuera de estas polarizaciones, las contribuciones brindadas por Schön $(1992)^{16}$, ampliamente difundidas, que subrayan la importancia de formación de profesionales reflexivos y critican la racionalidad técnica instrumental. Sin dudas, un profesional no resuelve los principales problemas humanos y sociales que enfrenta a diario por la mera "aplicación" el conocimiento sistemático, derivado de la investigación especializada. Requiere del pensamiento, de la reflexión y del juicio profesional metódico, a la luz de los problemas de la realidad y de los conflictos que enfrenta, incluyendo los dilemas éticos.

Pero también es sin dudas necesario que este profesional pueda contar o acceder a la información y los conocimientos públicos, como elemento para sus intervenciones. Mientras que esto parece ser común en algunas profesiones, no lo es tanto en el campo de la docencia, en especial aquellas ligadas a los desarrollos del diseño y los métodos de enseñanza.

Finalmente, es importante distinguir dos cuestiones básicas. Por un lado, la necesidad de formar docentes capaces de reflexión y de elaboración de alternativas, fortaleciendo su juicio y su papel de profesionales y aún de intelectuales en la organización de la cultura (GIROUX, 1990) ${ }^{17}$. Por otro, la necesidad de contar con criterios básicos de acción didáctica, que orienten las prácticas de enseñanza y permitan elegir entre alternativas, adecuándolas al contexto y los sujetos y contribuir a la transformación de las prácticas en los ámbitos educativos. Ambas cuestiones no son antagónicas ni excluyentes sino necesariamente solidarias.

\section{HACIA EL FORTALECIMIENTO DE LAS PRÁCTICAS DE ENSEÑANZA}

La enseñanza constituye una práctica social intencional de transmisión cultural inherente a las sociedades desde los orígenes de la historia, apoyando simultáneamente la dialéctica de la conservación y el cambio. La preocupación por realizarla de la mejor manera o de lograr sus propósitos ha sido siempre una constante, más aún desde que existen las instituciones formales de enseñanza y que la docencia se ha constituido en una profesión específica para desarrollarla. Revisando estas prácticas podremos observar que, en términos generales, la enseñanza implica:

$\checkmark$ Transmitir un conocimiento o un saber

$\checkmark$ Favorecer el desarrollo de una capacidad

$\checkmark$ Corregir y apuntalar una habilidad

$\checkmark$ Guiar una práctica
En cuanto proceso para lograrlo, la enseñanza supone una secuencia organizada de acciones en las que se manifiesta un doble propósito: lograr la transmisión social (instrucción) y desarrollar capacidades específicas y potencialidades de quienes aprenden (construcción activa) ${ }^{18}$.

Para que la enseñanza sea eficaz, se requiere del desarrollo de una diversidad de diseños integrales (incluyendo la generación de ambientes y recursos propicios para enseñar y aprender) y de métodos de enseñanza, como productos sistemáticos del conocimiento, la investigación, la experimentación y la experiencia. Sin embargo, las discusiones especializadas de estos últimos años han llevado a un desplazamiento de los métodos, considerados como el resultado de experimentos de laboratorio, aislados y de baja importancia para la realidad, siempre compleja, diversa y cambiante. En su lugar, se prefirió hablar de estrategias de enseñanza elaboradas de manera autónoma, creativa y contextualizada por los propios docentes. Aún más, dentro de esta perspectiva, muchas investigaciones sobre la enseñanza se dedicaron a desentrañar y descubrir qué hacían los docentes para enseñar (investigaciones de docentes novatos y experimentados, estudios del pensamiento del profesor etc.) en la búsqueda de hallar caminos para orientar las prácticas exitosas.

Sin dudas, todas estas contribuciones aportan en la comprensión de los fenómenos educativos, en particular para entender la complejidad de la enseñanza, la macro y micro-política en

\section{la enseñanza supone una secuencia organizada de acciones en las} que se manifiesta un doble propósito: lograr la transmisión social (instrucción) $y$ desarrollar capacidades especificas $y$ potencialidades de quienes aprenden (construcción activa) 


\section{el currículo avanzará más}

\section{cuando pueda reconocer su \\ base de conocimientos en}

las prácticas y las escuelas

puedan considerarse como

instituciones de experiencias y

desarrollos.

las instituciones y la mediación del profesor en las decisiones prácticas. Pero también pueden arrojar bastante confusión con consecuencias prácticas, no sólo para los profesores sino también para el desarrollo de la enseñanza misma.

Hoy existe cada vez más conciencia (y evitando toda disputa encerrada en la discusión de términos), que no hay contradicción entre métodos y estrategias de enseñanza. Los métodos constituyen estructuras generales, con secuencia básica, siguiendo intenciones educativas y facilitando determinados procesos de aprendizaje. Los métodos brindan, así, un criterio o marco general de actuación que puede analizarse con independencia de contextos y actores concretos. Pero un método no es una "camisa de fuerza" o una "regla a cumplir" ni el docente es sólo un pasivo seguidor de un método ni lo "aplica" de manera mecánica. Por el contrario, lo analiza y reconstruye, elaborando estrategias específicas para situaciones, contextos y sujetos determinados, seleccionando y elaborando los medios adecuados a sus fines.

Aún más, los docentes no sólo elaboran activamente sus estrategias de enseñanza, sino que lo hacen de acuerdo con sus estilos o enfoques personales, es decir, sus características propias, sus elecciones y sus formas de ver el mundo. De este modo, algunos docentes se sienten más cómodos con la participación de los alumnos en el proceso de enseñar y aprender, otros se sienten más seguros cuando ejercen mayor control del rendimiento y planifican detalladamente sus actividades, mientras que otros tienen dificultades manifiestas para cierto tipo de tareas (como realizar exposiciones verbales o dialogar con otros), entre otros variados estilos.

Muchos estudios y propuestas para la enseñanza y el aprendizaje, así como desarrollos concretos metodológicos han seguido produciéndose en forma constante, significativa y relevante. Ellos permiten avanzar hacia ciencia del diseño de la enseñanza, concebida a gran escala y en forma general, estableciendo cuidadosamente las condiciones que favorecen el aprendizaje y la instrucción. Su sentido es, sin duda, ayudar a los profesores a tomar sus propias decisiones en la elaboración de sus proyectos y en la concreción de la enseñanza.

Pero no todo lo mejor es siempre lo nuevo. Si bien los debates y los cambios de enfoques y contenidos para la enseñanza constituye una necesidad permanente, acompañando los nuevos desarrollos, no es necesario hacer una tabla rasa de las estructuras básicas de pensamiento y de acción didáctica. Ello puede significar la superación del abandono irreflexivo de toda tradición, distinguiendo las diferencias entre lo "nuevo" y lo "viejo", entre lo "caduco" y lo que aún permanece como válido. Esta distinción y la recuperación de los ejes básicos para la acción didáctica constituyen una respuesta a las necesidades vivas del desarrollo de la enseñanza (y de los maestros y profesores), para contribuir a su desarrollo en nuevas experiencias en las prácticas.

En el terreno de las prácticas institucionales, en sus distintas manifestaciones y ámbitos, se requiere fortalecer la enseñanza, entendiendo que ésta mejorará por y con la activa participación y elaboración de los profesores, adecuando las propuestas a los contextos y los grupos particulares de alumnos. Desde el currículo será necesario generar las condiciones que permitan potenciar la riqueza de la vida en las aulas, produciendo cambios que permitan que los profesores trabajen en equipo, intercambien sus experiencias e innovaciones. Como apuntaron Schwab y Stenhouse, el currículo avanzará más cuando pueda reconocer su base de conocimientos en las prácticas y las escuelas puedan considerarse como instituciones de experiencias y desarrollos.

\section{Notas:}

1 Entre los debates y las muchas producciones críticas del período, pueden recuperarse los aportes de CANDAU, Vera Ma. (Org) Rumo a uma nova didática. Petrópolis : Vozes, 1988; MARAGLIANO, R. et al. Teoria della didattica. Roma : Riuniti, 1978.

2 Todavía es vigente la problemática expresada, entre otros, por SAVIANI, Dermeval Saviani. Competência política e compromisso técnico (ou o pomo da discórdia e o fruto proibido). Rev. Educação e Sociedade, $n^{\circ} 15$, agosto de 1983.

3 SCHWAB, J. Un enfoque práctico como lenguaje para el curriculum. Buenos Aires: El Ateneo, 1973.

4 KEMMIS, S. El currículum: más allá de la teoría de la reproducción. Madrid: Morata, 1988.

STENHOUSE, L. Investigación y desarrollo del curriculum. Madrid: Morata, 1987.

6 DAVINI, M.C. Conflictos en la evolución de la didáctica. La demarcación de la didáctica general y las didácticas especiales. En: CAMILLONI; DAVINI; EDELSTEIN et al. Corrientes didácticas contemporáneas. Buenos Aires: Piados, 1996. Trad. al portugués, en Cadernos de Pesquisa, nº 98, Fundação Carlos Chagas, ago., 1996.

FELDMAN, D. Curriculum, maestros y especialistas. Buenos Aires : Del Quirquincho, 1994. 


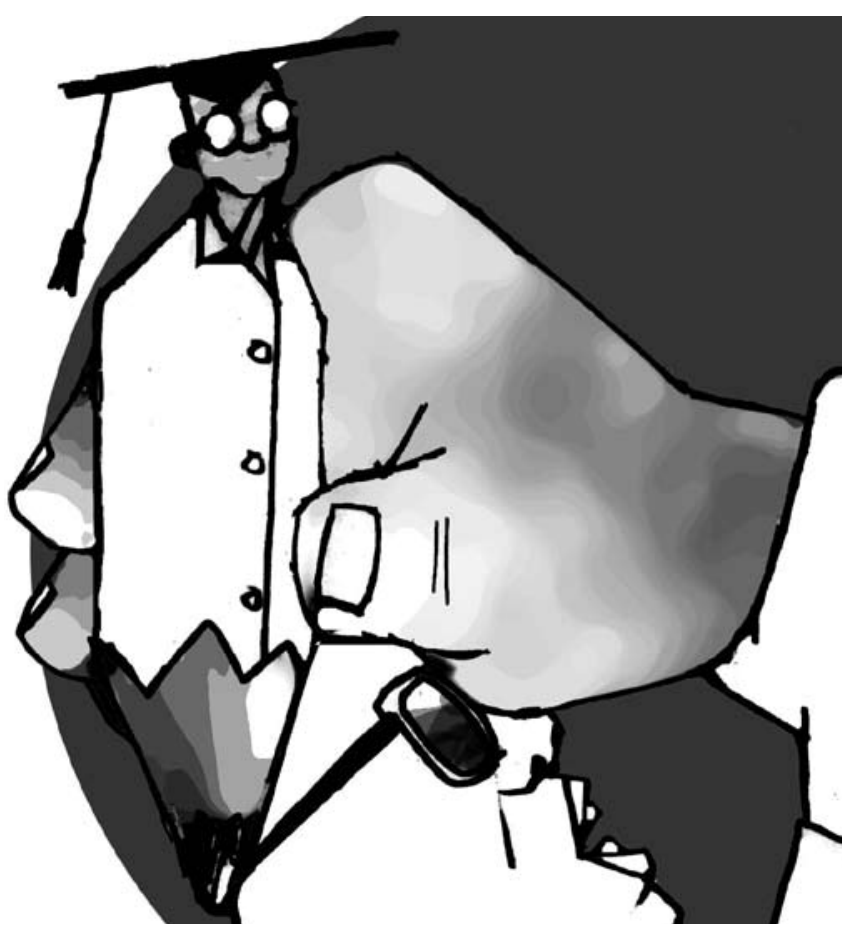

8 DAVINI, M. C. Métodos de enseñanza: didáctica general para maestros y profesores. Buenos Aires : Santillana, 2008.

9 GERTH, H.; WRIGHT, Mills. Ensayos de sociología contemporánea. Barcelona : Martínez Roca, 1989. p. 15.

${ }^{10} \mathrm{La}$ inclusión de la didáctica como disciplina del campo de la educación se manifiesta en la tradición europea, particularmente en Europa central y mediterránea. En los países de tradición anglosajona no es incorporada como disciplina. Pero ello no implica que se abandone el tratamiento de la enseñanza, desarrollándose una importante producción en materia de diseño de la instrucción.

11 BERNSTEIN, B. Clasificación y enmarcación del conocimiento educativo. Revista Colombiana de Educación, 1985.

12 APPLE, M. Ideología y currículum. Madrid : Edit. Akal, 1987 ; GIMENO SACRISTÁN, J. La pedagogía por objetivos. Madrid: Morata, 1982; KEMMIS, S., (1988), op. cit.; DAVINI, M. C. Modelos teóricos en la formación de docentes en el contexto latinoamericano. Revista Argentina de Educación, v.9, n. 15, 1991.

${ }^{13}$ GIROUX, H. Los profesores como intelectuales. Barcelona : Edit. Paidós, 1990.

14 GIMENOSACRISTÁN,J;PÉREZ GÓMEZ,A. Comprendery transformar la enseñanza. Madrid : Morata, 1996.

${ }^{15}$ CONTRERAS DOMINGO, J. La autonomía del profesorado. Madrid : Morata, 1996

${ }^{16}$ SCHÖN, D. La formación de profesionales reflexivos. Barcelona: Piadós, 1992.

${ }^{17}$ GIROUX, H. (1990), op. cit.

18 En términos generales, pueden reconocerse dos grandes perspectivas sobre la enseñanza. Una se asienta en la metáfora de la instrucción (desde los aportes de Vigotsky), enfatizando la transmisión de conocimientos y habilidades cognitivas, y otra se centra en la elaboración participativa. En realidad, ambas se diferencian por una cuestión de énfasis, dado que ambos procesos están implicados en la enseñanza y el aprendizaje.
ABSTRACT

Maria Cristina Davini. Teachers'education and didactics: building bridges to professional development and teaching.

The article makes a critical review of the contradictions between teachers' education and didactics maintained by the pedagogical discourse in the last few decades. Analyzing the risks of this separation, it asserts that critical commitment, reflection, and teachers' professional autonomy are not issues antagonistic to didactic education. On the contrary, the article emphasizes the value of basic criteria and rules for didactical action as the basis for teachers to make thoughtful and contextualized decisions.

Keywords: Teachers'Education; Didactics; Teaching; Profession.

\section{RESUMEN}

María Cristina Davini. Formación de profesores y didáctica: tendiendo puentes hacia el desarrollo profesional y de la enseñanza.

El articulo realiza una revisión crítica entorno a los desencuentros entre la formación de profesores y la didáctica sostenidos por el discurso pedagógico de las últimas décadas. Analizando los riesgos de esta separación, sostiene que el compromiso crítico, la reflexión y la autonomia profesional de los profesores no son cuestiones antagónicas a la formación didáctica. Por el contrario, destaca el valor de los criterios y reglas básicas de acción didáctica como base para las decisiones reflexivas y contextualizadas de los docentes.

Palabras clave: Formación de Profesores; Didáctica; Enseñanza; Profesión. 